\title{
Platelet Indices among Sudanese Pregnant Women with Medical Disorders Association; A Cross-sectional Study in Port Sudan City
}

\section{Bashir Abdrhman Bashir ${ }^{1}$, Hisham Hassan Dirar², Maisa Ahmed Badaneen $^{3}$}

\author{
${ }^{1}$ Secretary of Academic Affairs, Assistant Professor of Hematology, Chairman of Hematology Department, Medical \\ Laboratory Sciences Division, Port Sudan Ahlia College, Port Sudan, Sudan \\ ${ }^{2}$ Hematology Specialist, Health Insurance Corporation, Red Sea State \\ ${ }^{3}$ Clinical Chemistry Specialist, Laboratories management and Researches, Ministry of health, Red Sea State
}

\begin{abstract}
Pregnant women with medical disorders may associated with multiple changes in platelet indices parameters. It may be arising from hemodilution or increased platelet consumption during uteroplacental circulation. Platelet indices (PI) are a group of derived platelet parameters extracted as a part of the automatic complete hemogram. This study aimed to investigate the potential role of Platelets as a diagnostic or prognostic marker across the disease associated with Sudanese pregnancies. A cross-sectional study was conducted in March 2015 at Port Sudan Teaching Hospital, Port Sudan, Sudan. 40 Sudanese pregnant women with different medical complications were enrolled and 10 well pregnant women were included in this study. In both, platelet count (PLT), mean platelet volume (MPV), platelet distribution width (PDW), plateletcrit (PCT), platelet large cell ratio (P-LCR) and platelet cell concentration (P-LCC) were done. The pregnant women with medical association in compared with well pregnant women were found to be significant in the MPV, PDW, P-LCR, and P-LCC ( $\mathrm{P}<0.022,0.036,0.021$ and 0.040 respectively). In contrast, PLT and PCT were found to be insignificant $(\mathrm{P}<0.871$ and 0.666$)$. However, platelet indices were higher in patients than in controls except for the PLT and PCT level no changes were displayed. Accordingly, the convincing laboratory evidences in this study show that the usefulness of platelet indices as marker for medical disorders associated with pregnancy. The MPV and PDW are potential markers in the predicting disease severity.
\end{abstract}

Keyword: Platelet indices, MPV, PDW, Pregnant women, Port Sudan

\section{Introduction}

Platelets (thrombocytes) are a nucleated small discoid blood cells and considered a very high energy cell with metabolic rate 10 times that of an erythrocyte. It is originated from cytoplasmic fragments of bone marrow megakaryocyte, with a diameter of $1.5-3.5$ $\mu \mathrm{m}$ and volume up to $10.4 \mathrm{fl}$ (Turgeon, 2017; Budak, 2016). Each megakaryocyte giving rise approximately to $1000-5000$ platelets into the circulation where they have $9.0 \pm 1$ day survival time (Hoffbrand, 2016). Platelet has an active role in the vascular integrity repair and primary hemostasis. Thrombopathy may involve in the pathogenesis of many medical disorders associated with pregnancy (Velera, 2010). Thrombocytopenia is generally common in pregnant women compared to nonpregnant women. Rarely, become lethal and increased the mortality (Dundar, 2008). The platelet indices, plateletcrit, mean platelet volume, platelet distribution width, platelet large cell ratio, and platelet large cell concentration are a group of platelet parameters related to platelet morphology and proliferation kinetics (Budak, 2016). These indices recently have been used in the diagnosis and prediction of a lot of the kind of disease as well as diseases associated with pregnancy, particularly in the evolution of pre-eclampsia (PE). A substantial study has demonstrated crucial roles for platelets in the pathogenesis of various clinical conditions (Thachil, 2015). Many researches have been found a relationship between the changes in the platelets indices and the disease associated with pregnancy (Pughikumo, 2015; Nooh et al, 2015). To date, there has been no studies or published data expressed the role of platelet indices in Sudanese pregnant women. This study aimed to investigate and summarized the

This article is published under the terms of the Creative Commons Attribution License 4.0

Author(s) retain the copyright of this article. Publication rights with Alkhaer Publications.

Published at: http://www.ijsciences.com/pub/issue/2017-06/

DOI: 10.18483/ijSci.1338; Online ISSN: 2305-3925; Print ISSN: 2410-4477 
potential role of platelet as diagnostic or prognostic marker among Sudanese women with medical disorders associated with pregnancy.

\section{Materials and Methods}

\subsection{Study area and design}

Forty Sudanese pregnant women with medical disorders associated attended to the Port Sudan Teaching Hospital, the Obstetric gynecology department along with 10 Sudanese well pregnant women as control were recruited into the study. They came to the hospital in different stages of trimesters. This was a cross-sectional study performed on March 2015.

\subsection{Inclusion and exclusion criteria}

Sudanese pregnant women who were ill, blood pressure $\geq 140 / 90 \mathrm{mmHg}$, major surgery, high blood glucose, renal impairment eligible to include in this study. The exclusion includes Sudanese pregnant women with active bleeding from any sites and with known myeloproliferative neoplasm or panmyelosis.

2.3 Study parameters and sample

The platelet indices were estimated by semiautomated hematology analyzer (URIT 3010, E02211 PR China) on $3 \mathrm{ml}$ venous blood samples collected in di-potassium ethylene diamine acetic acid ( $\mathrm{K}_{2}$ EDTA) according to the international council for standardization in hematology (ICSH) recommends.
The method of venipuncture and the degree of accuracy of filling and mixing the sampling tube already taken into account, so that it was done properly.

The specimens were analyzed within I hour from venesection to avoid the interaction when EDTA collected samples are analyzed.

2.4 Data analysis

Estimation of laboratory data platelet indices of pregnant women with medical disorders was presented as mean \pm SD (standard deviation) and statistically tested by independent-sample $\mathrm{t}$ test and Pearson's Chi square test. P.value below 0.005 were considered significant. Data analyzed using a computer statistical package for social science (SPSS) software program version 24 (IBN, Chicago, USA).

\subsection{Ethical considerations}

This study was received ethical approval from Port Sudan Ahlia College, Hematology department and the Ministry of Health of Red Sea State. Written informed consent was obtained from all study participants.

\subsection{Platelet indices definition}

PI are group of platelet parameters determined together with automated complete blood count (CBC) profiles (Table 1).

\begin{tabular}{|c|c|c|}
\hline Parameter & Description & Unit \\
\hline PLT & Measure of the thrombocyte count & Microliter $(\mu \mathrm{l})$ \\
\hline MPV & Measure the thrombocytes volume & Femtoliter $(\mathrm{fl})$ \\
\hline PCT & The volume occupied by platelets in the blood & Percentage $(\%)$ \\
\hline PDW & Indicator of variability in size and activation & Femtoliter $(\mathrm{fl})$ \\
\hline P-LCR & Indicator of large platelet in the blood & Percentage $(\%)$ \\
\hline P-LCC & Indicator the concentration of circulating platelets & Percentage $(\%)$ \\
\hline
\end{tabular}

\subsubsection{Mean platelet volume}

It is the calculated measurement of the average size of platelet found in blood. The normal range is given as $7.5-10.4 \mathrm{fl}$ (Larsen, 2014).

\subsubsection{Platelet distribution width}

Is an indicator of volume variability in platelet size, changes with platelet activation and reflects the heterogeneity in the thrombocyte morphology (anisocytosis). Normal rage given is $9-13 \mathrm{fl}$ (Sachdev, 2014).

\subsubsection{Plateletcrit}

Is the volume (total platelet mass) occupied by platelets in the blood stream as a percentage. Volume of PCT varies depending on MPV and Platelet count according to the formula PCT $=$ PLT $\times$ MPV/10.000 (Charadrashekar, 2013).

\subsubsection{Platelet large cell ratio}

Is an indicator of circulated large platelets in size (> $12 \mathrm{fl}$ ), sometimes used to monitor the platelet activity. It is presented in percentage of normal range $15-35 \%$ (Hong, 2014).

\subsubsection{Platelet large cell concentration}

Is the actual concentration of that large platelet in the total platelet count (Budak, 2016).

\section{Results}

Sudanese pregnant women that enrolled in this study were aged between $18-45$ years (mean \pm SD $29.9 \pm$ 6.4). $7(17.5 \%)$ of the women were in their first trimester, $18(45 \%)$ in their second trimester, while $15(37.5 \%)$ were in their third trimester. The well pregnant controls were aged between 20 - 33 years (mean \pm SD 27.6 \pm 4.3 ). 
All patients (40) Sudanese pregnant women with medical disorders and (10) well pregnant women as control presented were screened for PLT, MPV, PCT, PDW, P-LCR, and PLCC levels. The pregnant women with medical association in compared with well pregnant women were found to be significant in the MPV, PDW, P-LCR, and P-LCC $(\mathrm{P}<0.022$, $0.036,0.021$ and 0.040 respectively). In contrast, PLT and PCT were found to be insignificant $(\mathrm{P}<$ 0.871 and 0.666) (Table 2).

However, platelet indices were higher in patients than in controls except for the PLT and PCT level no changes were displayed. A negative correlation was observed between MPV, PDW, PCT, P-LCR and P-
LCC and the trimester stages $(\mathrm{P}<0.445,0.132$, $0.355,0.580$ and 0.456 respectively). Figure 1 illustrates the overwhelming of platelet indices among trimester stages although the insignificancy.

The medical disorders associated with Sudanese pregnant women are summarized in (Table 3). It shows that diabetes mellitus (DM) represented the highest incidence $(27.5 \%)$ of the disease associated with pregnancy. The MPV and PDW were significantly demonstrated high in pre-eclampsia $(\mathrm{P}<$ 0.008 ) which pointed to that indices are very potential marker in PE indicating the platelet activity. PDW gives an account in DM on the platelet activity $(\mathrm{P}<0.016)$, but not the MPV $(\mathrm{P}<0.089)$.

Table 2 Comparison of platelet indices between Sudanese pregnant women with medical disorders and well pregnant women

\begin{tabular}{|l|c|c|c|}
\hline \multicolumn{1}{|c|}{ Parameter } & $\begin{array}{c}\text { Complicated pregnant } \\
\text { women } \\
(\mathbf{n}=\mathbf{4 0}) \\
\text { mean } \pm \text { SD }\end{array}$ & $\begin{array}{c}\text { Well pregnant women } \\
(\mathbf{n = 1 0 )} \\
\text { mean } \pm \text { SD }\end{array}$ & P. value \\
\hline PLT $\times 10^{3} / \mu \mathrm{l}$ & $240 \pm 74.5$ & $244 \pm 23.8$ & 0.871 \\
\hline PCT $\%$ & $0.22 \pm 0.05$ & $0.22 \pm 0.03$ & 0.666 \\
\hline MPV fl & $9.64 \pm 0.99$ & $8.85 \pm 0.71$ & $0.022^{*}$ \\
\hline PDW fl & $12.91 \pm 2.5$ & $11.1 \pm 0.97$ & $0.036^{*}$ \\
\hline P-LCR $\%$ & $23.9 \pm 7.3$ & $18.1 \pm 4.6$ & $0.021^{*}$ \\
\hline P-LCC $\%$ & $54.4 \pm 15.2$ & $43.6 \pm 10.8$ & $0.040^{*}$ \\
\hline
\end{tabular}

Table 3 List of medical diseases associated with Sudanese pregnant women

\begin{tabular}{|lr|}
\hline Disorders & Number (\%) \\
\hline PIH (Pregnancy induced hypertension) & $9(22.5 \%)$ \\
Pre-eclampsia (PE) & $6(15 \%)$ \\
Diabetes mellitus (DM) & $11(27.5 \%)$ \\
Abruptio placentae & $2(5.0 \%)$ \\
Toxoplasmosis & $1(2.5 \%)$ \\
Malaria & $2(5.0 \%)$ \\
Placenta previa & $2(5.0 \%)$ \\
HIV (Human immune virus) & $5(12.5 \%)$ \\
Hyperthyroidism & $2(5.0 \%)$ \\
\hline
\end{tabular}

\section{Trimester stages}

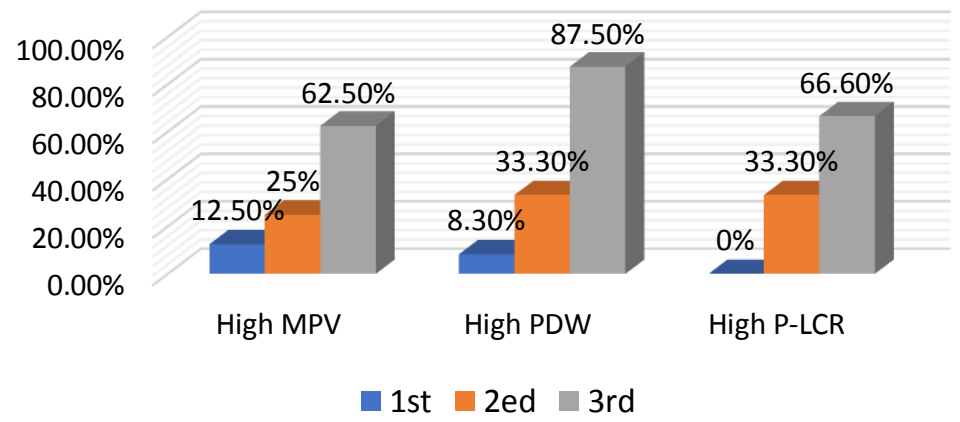

Figure 1 Platelet indices during the trimester stages 


\section{Discussion}

The measurement of all of the platelet indices simultaneously will provide a valid measure of disease severity as well as the new insight into the potential etiology in diagnosis and predicting that resulted in platelets indices changes.

In the present study, no changes in PLT and PCT were found in the Sudanese pregnant women with medical disorders and the Sudanese well pregnant women. These findings are similar to the study done in Ibadan, Nigeria by Obisesan et al, 1998. Our results highlight increasing MPV in the Sudanese pregnant women with medical disorders in compared to well pregnant women as a control $(\mathrm{P}<0.022)$ which indicate increased in the platelet diameter and simultaneously pointed to the production rate and the platelet activation. Similar study reported are consistent with our results (Narcie et al, 2013).

High MPV also reported by Nooh et al, (2015) statistically significant in the pre-eclampsia than normotensive pregnant women $(\mathrm{P}<0.003)$. The validity of alteration in the MPV in predicting preeclampsia has been extensively analyzed (Dundar et al, 2008). Many studies concluded that pregnant women with medical disorders with > MPV had an increased risk for developing pre-eclampsia (Jarmo et al, 2000). Moreover, they suggested that MPV stands as a potential marker for prediction of $\mathrm{PE}$ development (Jarmo et al, 2000).

A significant PDW increased was noted in our finding which is in agreement with those of previous studies (Yong, 2014; Freitas, 2013; Dadhish, 2012). Some conflicting finding has been published regarding the changes in the platelet indices in well pregnant women. Some researchers found no change in the values of these indices between patients and controls (Ceyhan, 2006, Freitas, 2013). Whereas others demonstrated difference in platelet index values (Yong, 2014; Dundar, 2008). This consistency of those studies may be due to the varying methods of platelet indices determination (Ceyhan, 2006).

P-LCR was significantly increased in patients with thrombocytopenia and decreased in thrombocytosis condition. It was inversely related to platelet count and directly related to MPV and PDW (Bobu, 2004). It was also being used in monitoring the platelet activation (Hong, 2014). Our study revealed high PLCR and P-LCC (derived from PLT and P-LCR) which were consistent with some findings of the Brazilian study (Santos, 2004).
The clinical significance and usefulness of some of these platelet indices still need more studies. The present study has limitations that need to be taken into consideration. First, the restriction to the enrollment, patients admitted to Port Sudan Teaching Hospital. Second, the very limited number of medical disorders associated with pregnancy in this study. Regrettably, the platelet functions weren't performed in this study should be included in other studies.

Ultimately, the convincing laboratory evidences in this study show that the usefulness of platelet indices as marker for medical disorders associated with pregnancy. Abnormalities of increased MPV, PDW and P-LCR may suggest changes of platelet functions. The clinical uses of platelet indices, as markers of the disease spectrum. The MPV and PDW are potential markers in the predicting disease severity.

\section{References}

1. Babu E and Basu D (2004). Platelet large cell ratio in the differential diagnosis of abnormal platelet counts. Indian J Pathol Microbiol 47(2): 202-205.

2. Budak YU, Polat M, Huysal K (2016). The use of platelet indices, plateletcrit, mean platelet volume and platelet distribution width in emergency non-traumatic abdomina surgery: a systematic review. Boichemia Medica, 26 (2): $178-93$.

3. Ceyhan T, Beyan C, Baser I, et al. (2006) The Effect of Preeclampsia on Complete Blood Count, Platelet Count and Mean Platelet Volume. Annals of Hematology, 85, 320322.

4. Chandrashekar V (2013). Plateletcrit as a screening tool for detection of platelet quantitative disorders. J Hematol. 2: 22 -6 .

5. Dadhich S, Agrawal S, Soni M et al (2012) Predictive Value of Platelet Indices in Development of Preeclampsia. Journal of SAFOG with DVD, 4, 17-21.

6. Dundar O, Yoruk P, Tutuncu L, et al. (2008) Longitudinal Study of Platelet Size Changes in Gestation and Predictive Power of Elevated MPV in Development of Preeclampsia. Prenatal Diagnosis, 28, 1052-1056.

7. Freitas LG, Alpoim, PN, Komatsuzaki, F et al (2013) Preeclampsia: Are Platelet Count and Indices Useful for Its Prognostic? Hematology, 18, 360-364.

8. Hoffbrand V, Moss PAH (2016). Essential Haematology. $7^{\text {th }}$ ed. WILLY-BLAKWELL, India, pp $265-266$.

9. Hong H, Xiao W, Maitta RW (2014). Steady increment of immature platelet fraction is suppressed by irradiation in single-donor platelet components during storage. PLoS One. eb5465.

10. Järemo P, Lindahl T.L, Lennmarken C, et al. (2000) The Use of Platelet Density and Volume Measurements to Estimate the Severity of Preeclampsia. European Journal of Clinical Investigation, 30, 1113-1118.

11. Larsen SB, Grove EL, Hvas AM, Kristensen SD (2014). Platelet turnover in stable coronary artery disease-influence of thrombopietin and low grade inflammation. PLoS One. e85566.

12. Narcie H, Turk E, Karagulle E, Togan T, Karabulut K (2013). The of mean platelet volume in the diagnosis of acute appendicitis: a retrospective case-controlled study. Iran Red Crescent Med J. 15E11934. 
Platelet Indices among Sudanese Pregnant Women with Medical Disorders Association; a Cross-sectional Study in Port Sudan City

13. Nooh AM, Abdeldayem HM (2015). Changes in Platelet Indices during pregnancy as potential markers for prediction of preeclampsia development. Open Journal Obstetric Gynecology. 5, $703-12$.

14. Obisesan KA, Adeyemo AA, Okunade MA (1998) Haematological values in pregnancy in Ibadan, Nigeria. Afr J Med Sci 27 (1-2): 9-11.

15. Pughikumo OC, Pighikumo DT, Iyalla C (2015). Platelet Indices in pregnant women in Port Harcourt, Nigeria. IOSR Journal of Dental and Medical Sciences. 14 (3): 28 - 31

16. Sachdev R, Tiwari AK, Goel S, Rania V, Sethi M (2014). Establishing biological reference interval for novel platelet parameters (immature platelet fraction, high immature platelet fraction, platelet distribution width, platelet large cell ration, Platelet-X, plateletcrit, and platelet distribution width) and their correlation among each other. Indian Journal Pathol Microbiol. 57: 23 - 15.
17. Santos EV, Meirelles FJ (2004). Measurement of platelet parameters in normal and pre-eclamptic pregnant women. Rev Bras Ginecol Obstet, 26 (3): 201-206.

18. Thachil J (2015). Platelets in inflammatory disorders: a pathophysiological and clinical perspective. Semi Thromb Hemost. 41: $572-81$.

19. Turgeon ML (2017). Clinical Hematology: theory and procedures. $6^{\text {th }}$ ed. Wolters Kluwer Health. Lippincott Williams and Wilkins, China, pp $654-657$.

20. Valera M, Parant O, Vayssiere C, Arnal JO, Payrastre B (2010). Physiologic and Pathologic changes of platelets in pregnancy. Platelets, 21 (8): 587-595.

21. Yong S.W, Cho S.H, Kwon H.S, et al. (2014) Significance of the Platelet Distribution Width as a Severity Marker for the Development of Preeclampsia. European Journal of Obstetrics \& Gynecology and Reproductive Biology, 175, 107-111. 